\title{
Social Networking for Web-Based Communities
}

\section{Tomayess Issa}

\author{
Curtin University \\ GPO Box U1987 \\ Perth Western Australia 6845

\section{Piet Kommers} \\ University of Twente, \\ P.O. Box 217, 7500 AE Enschede, the Netherlands \\ E-mail: Kommers@edte.utwente.nl
}

\begin{abstract}
In the 21st century a new technology was introduced to facilitate communication, collaboration, and interaction between individuals and businesses. This technology is called Social Networking; this technology is now part of Internet commodities like email, browsing and blogging. From the 20th century until now the Internet has shaped the way organizations, academics and health sectors to interact, communicate, connect, and exchange knowledge around the world. Social Networking can reduce enterprises cost, increase profit, and assist to develop new communication forms between consumers, stakeholders, vendors, suppliers, universities and health departments. However, this technology can create new challenges for education and its governance and management. Social networking is considered a precursor to the new 3D virtual presence that will gradually supplant the telephone and video conferencing and finally even the face-to-face communication. This article examines these opportunities, challenges, and threats of social networking in organization, education and health care sectors.
\end{abstract}

Keywords: Social networking, virtual communities, organization, education and health sectors

Reference to this paper should be made as follows: Issa, T., Kommers, P. 'Social Networking for Web-Based Communities', Int. J. Web Based Communities, Vol. X, No. Y, pp.000-000.

Biographical notes: Dr. Tomayess Issa is a Senior Lecturer, Postgraduate Course Leader and Postgraduate Online Coordinator at Curtin University, Australia. Tomayess has vast experience in Australian tertiary education, teaching HCI and Usability, Social Network, Sustainability and Green IT and Networking. Tomayess completed her doctoral research in Web development and Human Factors, and published several journals and conferences based on her PhD's results and teaching research. Tomayess is a member of an international conference program committee, and she is currently conduct research locally and globally in information systems, HCI, Usability, Internet, Sustainability and Green IT, social network and teaching and learning.

Dr. Piet Kommers is an Associate Professor at the University of Twente. His specialties are advanced learning tools such as concept mapping, virtual reality and mobile learning. His research and teaching stretches from teacher education via the European Joint Research Projects to international projects under the auspices of UNESCO. His recent publications are on learners' preconceptions and representations that express pre-intuitive ideas before the actual learning may start: Cognitive Support for Learning and Imagining the Unknown. $\mathrm{He}$ is the Editor of several research journals and organizes conferences in mobile learning, e-society and web-based communities. 


\section{Introduction}

Internet has changed human experience in interaction and collaboration, as internet becomes an essential technology for individuals, corporate enterprises and health sectors. These sectors are using this technology to access the required information, education, entertainment, marketing, political, social, sell and buys products and watch television. Besides using the internet, these sectors shifted their attention to other technologies alike social networking. Social networking is a 'particular consumption of digital media or internet that has little to do with traditional informational media use, using the social networking provides a mechanism for the audience to connect, communicate, and interact with each other and their mutual friends though instant messaging or social networking site' (Correa et al., 2010, p. 247 - 248). The contribution of social networking is to promote unforeseen benefits and decrease traditional costs like face-to-face meetings and expensive marketing campaigns (Kelin, 2008). However, social networking also introduces new threats like security, privacy, workload, legal conflicts, risking reputation etc.(Harris, 2010 , Amichai-Hamburger and Hayat, 2011, Mitchell et al., 2011, Bryne and Lee, 2011 ). This study seeks to expand the literature review by investigating the relationship between personality and social use and discuss the positive and negative effects of social networking usage on individuals, organizations, and education and health sectors.

\section{Background}

Social networking has been labelled as the new social mechanism driven by justin-time communication and the mentality to share. Internet and Social Networking are introduced to the broader public as a potential social revolution. Hansen, Shneiderman \& Smith (2011) indicate that social networking technologies have created new numerous platforms of interacting i.e. social networking, text messaging, shared photos, podcasts, streaming videos, wikis, blogs and discussion groups (Hanna et al., 2011). Currently, the world population is seven billion people, while internet users are two billion and greater than one million are social network users. It was noted that Western Europe lags behind in social network penetration, while the markets in Brazil, China and India show the highest awareness and penetration of social networks. This means that $>70 \%$ of internet population are using social networking sites for personal and organization usage (Rosenberg, 2011, Internet World Stats, 2011, Wauters, 2011). According to Wauters (2011) social networkers are member of networks on average, in Europe is 1.9, USA 2.1, Australia 1.5, Japan 1.8 Brazil: 3.1, India 3.9, and finally in China is 3.4. These figures indicated that India, China and Brazil have a higher social network penetration compared to USA, Australia, Japan and Europe.

Various types of social networking sites are available on the internet providing facilities to organizations and individuals. These sites are divided into six types: 1) profile-based, which holding information about individuals i.e. profile, pictures, links. 2) Content-based, examples of these services are: Flickr, Shelfari, Youtube.com, last.fm. 3) White label, this service will allow users to form their own mini communities within sites, i.e. PeopleAggregator and Ning. 4) MultiUser Virtual Environments, this service will allow users to interact with others, an example for this service, i.e. SecondLife and WorldofWarcraft. 5) Mobile Social network sites: an example for this service is MySpace and Twitter offer mobile phone versions of their services, sharing information and knowledge between users via their phones. Furthermore under this service there is another platform i.e. MYUBO which allow users to share and view video over mobile networks. 6) Micro-Blogging/Presence updates: Micro-blogging services such as 
Twitter and Jaiku allow users to publish a short message publicly or within contact groups. 7) Social search engines: is an important web development which utilizes the popularity of social networking services. An example i.e.: Wink and Spokeo (Medaglia et al., 2009, Digizen.org, n.d).

According to Alexa (2011) the ten global websites for 2011 are: Google; Facebook; YouTube; Yahoo!; Wikipedia; Baidu.com; Blogger.com; Windows Live; Twitter; QQ.com. Malita (2011) added more social networking websites which are offering similar facilities from interaction, collaboration and communication i.e. MySpace; Gather.com (social networking); Second Life (virtual reality); Digg (news sharing); Flickr (Photo Sharing) and Miniclip (game sharing). Recent studies (Buck, 2011, Wauters, 2011) indicate that Facebook and Twitter are considered the main social networking sites in USA, Brazil, Europe, China, India, Japan and Australia (see Table 1). In addition, that more people around the world are using Facebook compared to Twitter that is only used by $16 \%$ of the population while the awareness for Twitter is $80 \%$ (Wauters, 2011).

\begin{tabular}{|c|c|c|c|c|c|c|c|}
\hline $\begin{array}{l}\text { Social } \\
\text { Networking } \\
\text { Usage }\end{array}$ & USA & Brazil & Europe & China & India & Japan & Australia \\
\hline Membership & $\begin{array}{l}\text { Facebook: } \\
70 \% \\
\text { Twitter: } \\
20 \%\end{array}$ & $\begin{array}{l}\text { Facebook: } \\
59 \% \\
\text { Twitter: } \\
34 \%\end{array}$ & $\begin{array}{l}\text { Facebook: } \\
62 \% \\
\text { Twitter: } \\
16 \%\end{array}$ & $\begin{array}{l}\text { Facebook: } \\
17 \% \\
\text { MySpace: } \\
14 \%\end{array}$ & $\begin{array}{l}\text { Facebook: } \\
77 \% \\
\text { Twitter: } 41 \%\end{array}$ & $\begin{array}{l}\text { Facebook: } \\
13 \% \\
\text { Twitter: } \\
29 \%\end{array}$ & $\begin{array}{l}\text { Facebook: } \\
63 \% \\
\text { Twitter: } 12 \%\end{array}$ \\
\hline Awareness & $\begin{array}{l}\text { Facebook: } \\
93 \% \\
\text { Twitter: } \\
77 \%\end{array}$ & $\begin{array}{l}\text { Facebook: } \\
87 \% \\
\text { Twitter: } \\
76 \%\end{array}$ & $\begin{array}{l}\text { Facebook: } \\
96 \% \\
\text { Twitter: } \\
80 \%\end{array}$ & $\begin{array}{l}\text { Facebook: } \\
59 \% \\
\text { MySpace: } \\
54 \%\end{array}$ & $\begin{array}{l}\text { Facebook: } \\
93 \% \\
\text { Twitter: } 90 \%\end{array}$ & $\begin{array}{l}\text { Facebook: } \\
74 \% \\
\text { Twitter: } \\
76 \%\end{array}$ & $\begin{array}{l}\text { Facebook: } \\
94 \% \\
\text { Twitter: } 85 \%\end{array}$ \\
\hline $\begin{array}{l}\text { Country's } \\
\text { Population }\end{array}$ & $528,720,588$ & $190,732,694$ & $738,523,843$ & $1,341,403,687$ & $1,205,910.000$ & $\begin{array}{l}127,380,00 \\
0\end{array}$ & $22,769,704$ \\
\hline
\end{tabular}

Table 1 Social Networking Usage - Membership, Awareness, and the Country’s population

Social networking sites' usage by individuals and organizations has improved from enterprise-wide collaboration, communication and productivity without graphical boundaries (Swensrud, 2011, Lin and Lu, 2011, European Travel Commission, 2011, Kane et al., 2010, Forrester Resarch, 2010). Besides connecting with others, getting information about new/current products and brands is driving membership of social networks (Wauters, 2011). It was distinguished that social networking sites started to replace the email and other means of online communication to online chatting, and posting the latest information in relation to company's brands and products. Majority of consumers and stakeholders found out using this method is more convenient and efficient compared with the traditional method (Anonymous, 2009, Bennett et al., 2010, Burrus, 2010, Langheinrich and Karjoth, 2010).

Social networking is playing a major role in various sectors from management, marketing, recruiting and screening job application, sharing information and knowledge, disaster recovery, education, and health. For this study, the researchers will examine and investigate the social networking role in the education, organizations and health sectors since social networking usage can develop/enhance communication and collaboration and afford new opportunities for these sectors. Based on the recent trends and its extrapolations it seems as a more realistic characterization to label it as a catalytic role in on-going rather than essential new mechanisms. In other words: it is the speed, rather than the direction that is affected by the coming of social media. Using this technology is evolutionary rather than revolutionary nature may become clear from its shift in speed, scope, scale, and social heterarchy rather than hierarchy. The latter aspect 
is the growing awareness that social status and reputation get more and more specific for particular human capacities. Social networking usage in education, business, health and by individuals has defined a variety of 'networked tools or technologies that emphasize the social aspects of the internet as a channel for communications, collaboration, and creative expression, and is often interchangeable with the terms web 2.0 and social software' (Dabbagh and Kitsantas, 2011, p.1). Social networking usage offered various services as social networking has speed up on-going trends like globalization, the 24 hours economy, inter rather than intra-personal cognition and the empowerment of brittle stages on group formation and businesses.

Kietzmann et al.(2011) posit that using social networking will create and develop interactive platforms as employers and employees, individuals and communities can share, create, discuss, interact, connect, collaborate in various issues by using this platform. Furthermore, one notable change that has been brought by the social networking website usage is the new wave of informal and user friendly relationship between employers and employees, competitors, suppliers and investors, as this type of relationship will escalation trust and satisfaction between both parties (DiStaso et al., 2011). Sharing the social networking experience with these sectors is easier, faster, effective and more efficient, however, training and implementing will take time, as both employers and employees must provide the necessary service and assistance to their consumers and stakeholders continuously (Dabbagh and Kitsantas, 2011, DiStaso et al., 2011). This study will emphasize how social networking websites is offering unexpected new reaches towards transforming in the traditional fields. However, it was noted that ICT mindedness has already been assimilated in the various application domains and allow these sectors to evolve based on the combined thinking from the both parties, from end and ICT solutions simultaneously (see Figure 1).

Figure 1: Social networking and sectors

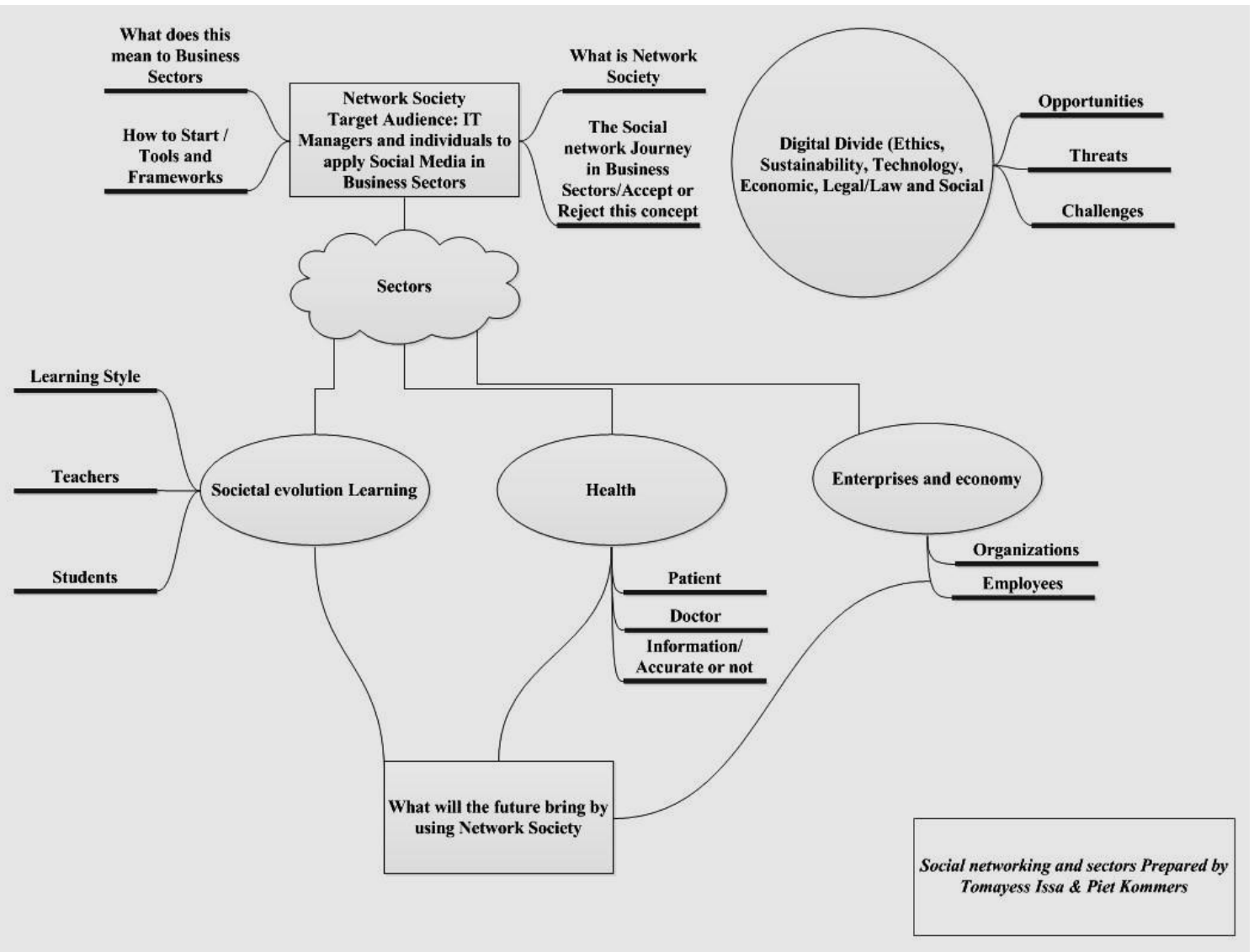




\section{Focus of the Research}

In order to find a stable perspective, the Educational sector will be taken as key focus in this study. Looking from the recent shifts in education it is possible to look to subsequent effects in Health and Corporate Enterprises.

- The transfer from educational evolution to health will be described in terms of new formats for doctor-patient communication; Patients have a much more extensive understanding of medical knowledge and many of them are computer-literate so that they can find alternative approaches on the web. While in the recent past this communication was conceived just for "conveying the message" it is now a decisive stage in the medication plan: Is the patient fully aware of the spectrum of alternative medications and potential types of interventions? What implications can be estimated when certain alternative approaches are chosen? Etc.

- The transfer from educational evolution to Corporate Communication and the benefits from Communities of Practice. Furthermore, a strong impact of changed educational culture on the way work, innovation and learning becomes intertwined. As school promotes youngsters to develop understanding in teams via games and simulation models, it is inevitable that the future employee will manifest as a team player rather than a soloist. This goes together with the growing need for more interdisciplinary approaches in problem solving and design. Communities of Practice (CoPs) as defined by Wenger, White \& Smith (2009) are the best description of how this 'Corporate Learning' may evolve in the next decades.

The approach to take the educational sector as prime perspective is not a trivial one; Institutional learning faces the problem of inertia caused by assessment methods from before. The real incentive for education to evolve is the fact that current students are supposed to be competitive in the knowledge economy of tomorrow. Parents and students rapidly understand this new need.

\section{Discussion}

Under the label 'Sectors' the researchers will explore and discuss social networking impacts in the three societal sectors, and identify the opportunities, challenges and threats by adopting this technology in their work. The first sector is Societal Evolution in Education, under this sector; the researchers will discuss it from the perspectives of learning-/teaching style. The second sector is Enterprises and Economy, as the researchers will focus on the aspects of innovation and the effects of Communities of Practice i.e. organizations and employees. The third sector is Health. It will be monitored on the aspects of doctor-patient communication (see Figure 1). From the teacher's perspective, social networking integration in teaching sector will generate new awareness and acquaintance for both teachers and students: 1) new teaching approaches, 2) gaining new different skills, and 3) collaboration and real world activities will be industrialized. A recent study (Zamorano et al., 2010, Struck et al., 2011) confirm that social networking integration in the teaching pedagogy and curriculum will enhance/develop teaching styles and meeting students' needs i.e.: 1) using blended teaching to ensure that classes are more interactive and collaborative between students compared with the traditional teaching methods; 2) autonomous learning vs being taught: under this category students will start 'learning how to learn' by reading, analysing and synthesising articles, completing some class activities and presenting their finding to their colleagues during the class. 
This technology will encourage especially the shy students to participate, engage in the learning process, and move their thinking outside the box. 3) Good reputation will be raised for the teachers who are willing/ using new techniques in their teaching process, and this will attract more students to her/his class. 4) Also new teaching styles will be developed to match the new generation needs, i.e. generation Y. Beside the above, teachers will develop their skills in respect to communication, cutting edge knowledge, research, and sharing the latest knowledge from locally and globally perspectives between her/his students. Furthermore, using social networking will allow for further collaboration between teachers nationally and universally especially to teaching, research grants, conferences, and journals. Finally, a new concept will be available is the real world. Under this concept teachers will utilize the virtual world/second life in their teaching and research to make their teaching more challenging and exciting to her/his students. Finally, Waddington (2011, p.14-15) pose that 'by incorporating social networking into lessons, teachers model and teach their students digital citizenship which is what students need to know to engage in activities on the internet in a constructive, beneficial, and appropriate fashion'.

Figure 2: Teacher's Perspective - Positive

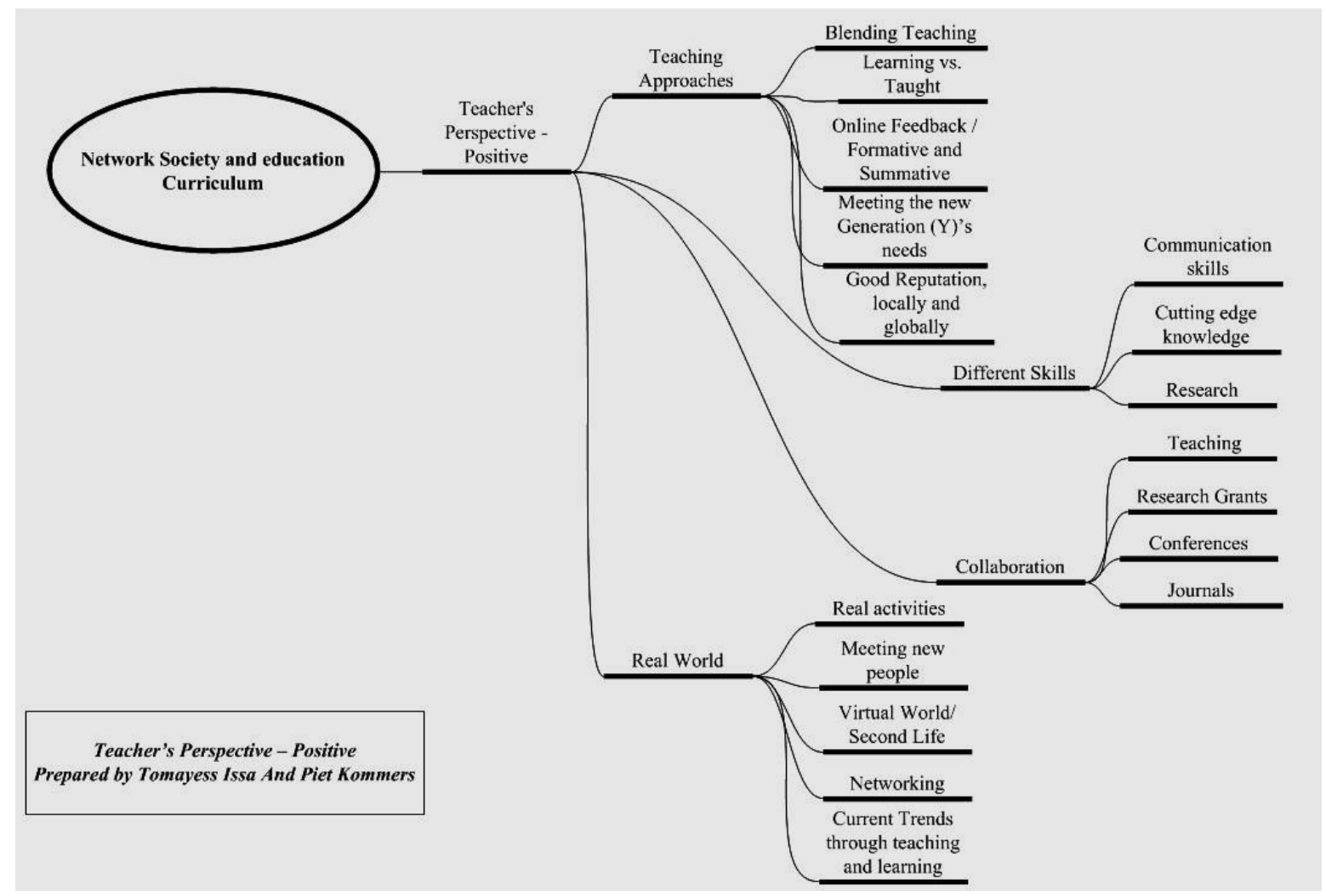

On the other hand, adopting social networking in teaching will transform teachers' expectation in the following aspects: 1) Culture; 2) Gender; 3) Workload; 4) Training; 5) Ethics Issues and Social Hacking. Culture aspect will affect the teaching delivery, as specific universities and nations having mix reaction toward social networking integration in their teaching pedagogy and curriculum, as culture can assist or prevent this integration, since some nations are mild toward this integrating in their curriculum for the following aspects: workload, culture and custom aspects, privacy and security (Forrester Resarch, 2010, Weaver and Morrison, 2008). Both gender and age are playing a major role in social networking teaching delivery, as majority of academics are coming from various generations i.e.: baby boomers, and generations $\mathrm{X}$ and $\mathrm{Y}$. Each 
generation has different needs and requirements in respect to training and workload. Therefore, the concerns behind social networking adoption in teaching are unlimited to culture, gender and age, however, workload, training and ethics issues are part of these limitations. A current research (Bennett et al., 2010, Forrester Resarch, 2010, Langheinrich and Karjoth, 2010) indicate that using social networking in teaching sector will increase teachers' workload from training/learning new concepts about social networking, and new materials must be added to his/her lecture notes and activities to match social networking needs. Furthermore, from Figure 3, working with social networking is unlimited to the workload, ethics and social hacking, there are other aspects need to be consider in relation to motivation, security, privacy, control and access (Hew, 2011).

Figure 3: Teacher's perspective - Negative

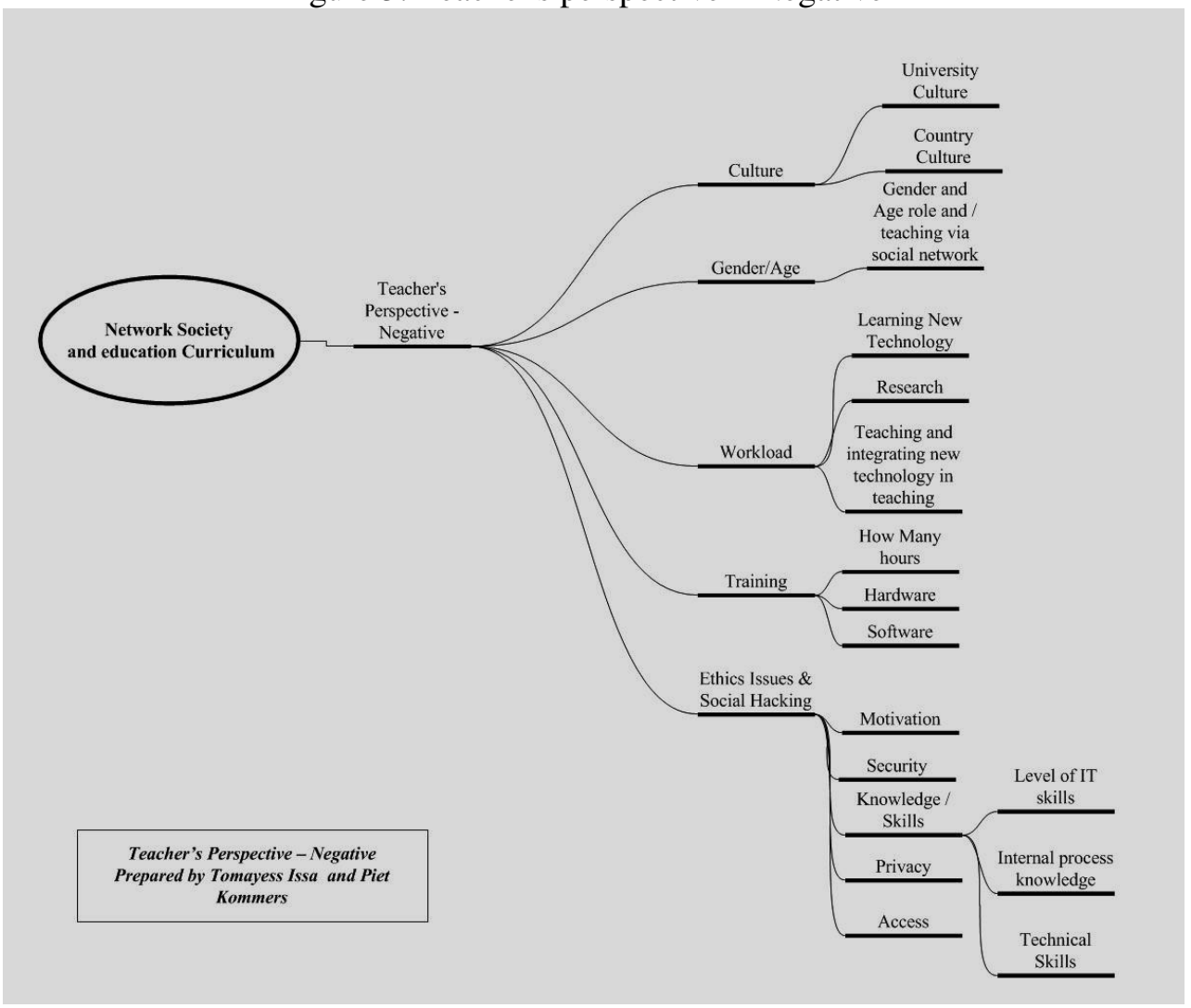

From the student's perspective, the literature review (Dabbagh and Kitsantas, 2011, Thompson et al., 2008) confirm that working and learning with social networking will bring new opportunities for students in respect to the crosssectional relationships, collaboration, real world and learning different skills (see Figure 4). Students will have the authority and chance to select his/her peers based on the study (or work) experience, research interests, artistic, talents, sport and others. Using this technology will develop more collaboration between students not only locally but globally simultaneously. Finally, the social networking will foster students' independent learning, as new skills will cultivate from communication, cutting edge and research. Using these skills rapidly will allow students to develop these skills for the current study and as well as for the real world life. Finally, several studies echoed (Van Deursen et al., 2011, Verdick.org;, 2011, Baams et al., 2011 ) that students will have the chance to meet new people, building new networking, and using the second life for learning purpose or fun. 
Figure 4: Students' perspective - Positive

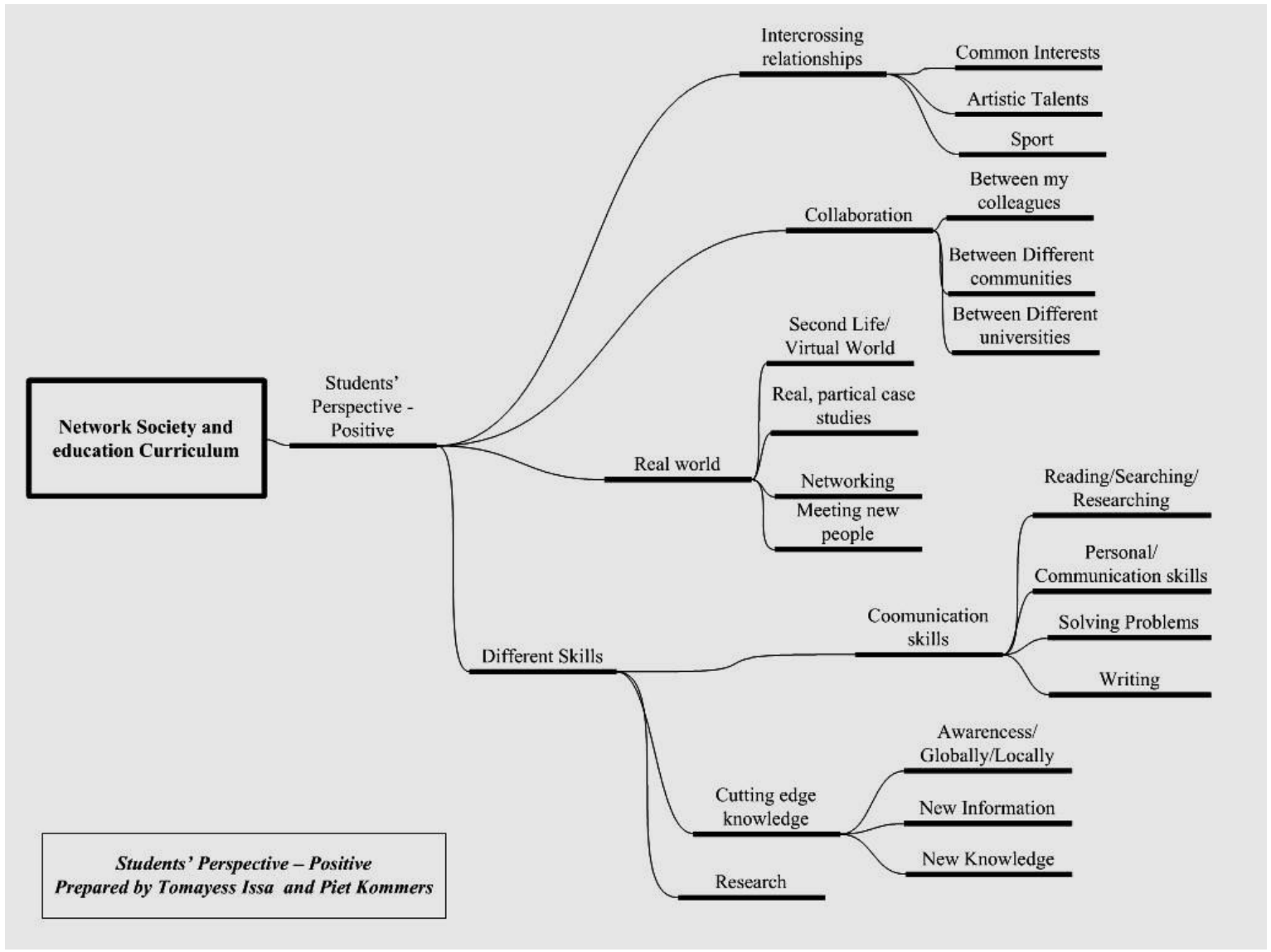

However, social networking is unrestricted to the benefits; however, integrating it in the teaching sector will develop new challenges and threats to both students and teachers simultaneously. Kaya (2010) posit that social networking integration in the education will establish peer-student networks prior to students arriving on campus in ways that may not have been previously possible without the affordances of new networking. From the students' perspective, the social networking will affect students ability in learning as majority of them will become lazy, lonely, depress, stress, and lack of concentrating in reading and searching, and face of face contact between friends and family will be dissolved (Carr, 2008, Walther et al., 2010 ). Furthermore, social networking will generate new academic problems for students in relation to reports and essay writing, proofreading and the most significant aspect is grammar. Currently majority of students are depending more and more on the internet facilities to finalize and complete their assessments, and majority of these websites are lacking the writing and grammar standards and this will influence students ability in his/her assessment presentation (see Figure 5).

Several studies (Kearns and Frey, 2010, Lee, 2009 , Shaw and Gant, 2002, Sun, 2011, Mokhtari et al., 2009 ) confirm and posit that these skills are essential not only for the university life but for future life as well. Therefore, incorporation the social networking principles in teaching will enhance these skills not decrease them. However, to achieve this in the university life, a good collaboration must be carried out between teachers and students to address these concerns, and to understand how the integration in curriculum and units will assist students in their university study, workplace in the future, and life in general without harming the writing and grammar standards.

Figure 5: Student's Perspective - Negative 


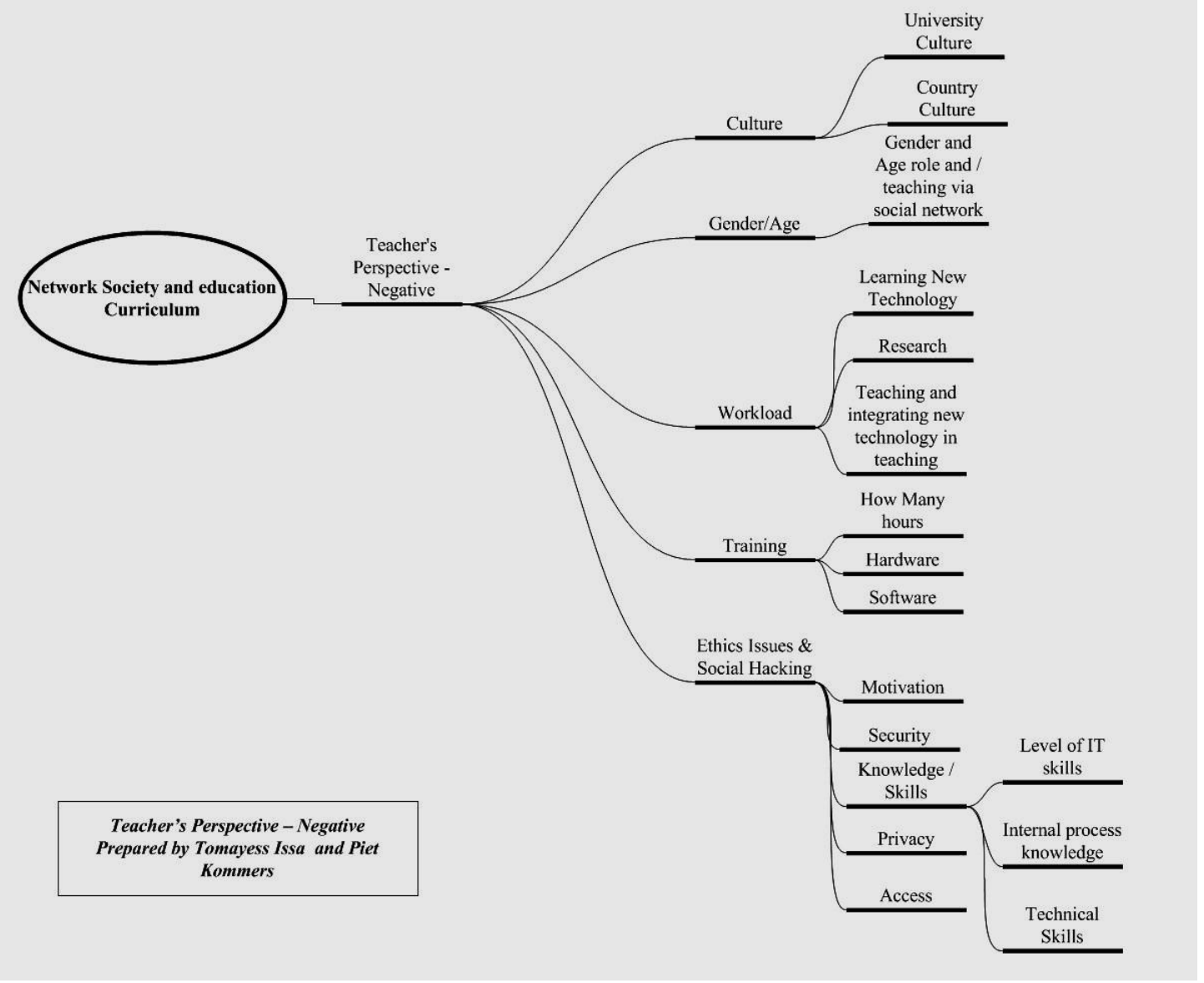

From the organization's perspective, using social networking in the organization sectors will construct new opportunities in organizations nationally and universally, as organizations will become more creative, innovative and ingenious. Beside the above, using social networking in the organizations will allow for more interaction and engagement between customers/stakeholders as it will give them the chance to participate in the strategic planning process and moving their meeting from traditional meeting (face to face) to the new interaction which is online. Beside that more interaction between employees will occur across geographical boundaries, and employees' knowledge and cutting edge will cultivate (see Figure 6). DeAndrea et al.(2011, p.2) indicate that social networking usage enable the "mass dissemination of messages, reduce the constraints of geographical dispersion and facilitate the record ability of communication'.

Adopting social networking in organizations will develop new culture in the organization, as employers and employees will have the chance to interact internally and externally to exchange ideas and sharing new knowledge and cutting edge with their consumers/ stakeholders regarding company brands and new knowledge and information. Wauters (2011) indicate that employees are consider as brand ambassadors to share information about their new products or services and announce company events. Several studies (Verhoevan et al., 2011, Swensrud, 2011, Rosenberg, 2011, Malita, 2011, Lin and Lu, 2011, Wauters, 2011) indicate that positive brand experiences by social networking campaign will have highest impact on brand perception and buying intention. 
Using the social networking in organizations, employees will become more innovative and creative, while organizations will build an excellent prestigious reputation constructed on their achievements and successes. Moreover, social networking integrating in organizations strategy will attract and retain best employees to work, and preserve internal and external recruitment for projects or initiatives which will be available based on their request.

Figure 6: Organization social network - Benefits

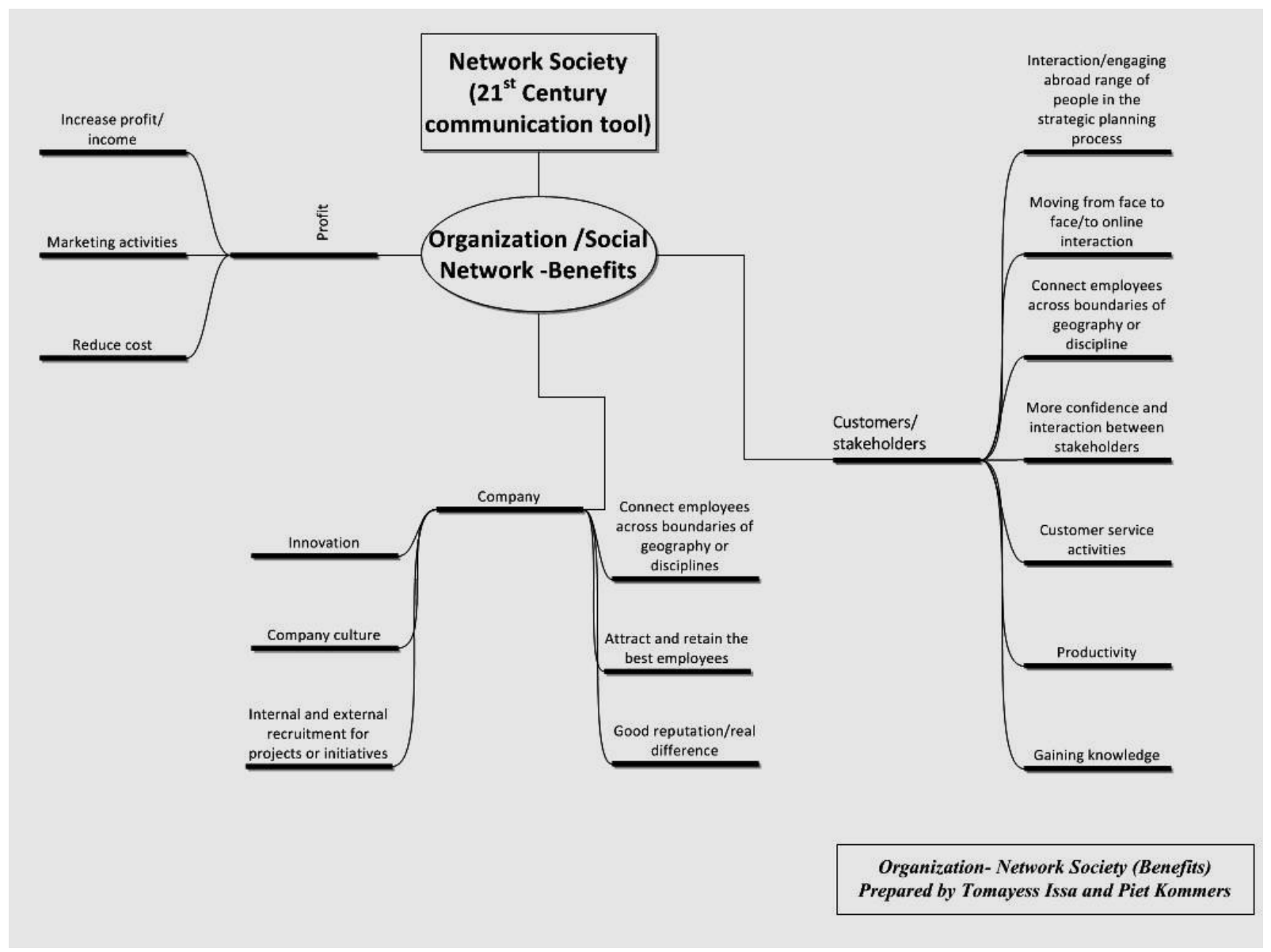

Additionally, consumers and stakeholders are playing a major role in the social networking present in the organization. From the organizations' perspective, there are various concepts behind social networking usage in the organization sector which are: interaction, customers' service activities, and productivity. This technology will assist to develop informal interaction, communication and collaboration between organization and consumers, as employees will start to share organization brands and the latest information and knowledge with their consumers. For example, the interaction between organizations, employees and consumers will encourage them to involve more in the organizations' strategies especially the marketing perspective. Wauters (2011) indicate that consumers would like to be more involved in the marketing, creating, innovating of organizations' brands and the most concept to start conversations. Currently, organizations' brands are available on social networking, and this will encourage consumers to try them by using various platforms i.e.: recommendation from friend, invitation by network contact, search engine, advertising on social networking, online advertising, buying intention, and traditional advertisements. Sharing the positive and negative brand experiences on social networking by consumers will invite more consumers to purchase/reject these information/ products, companies or brands since consumers trust each other most (Bennett et al., 2010, Forrester Resarch, 2010, Langheinrich and Karjoth, 2010, Lester and Perini, 2010, Lin and Lu, 2011, Wauters, 2011, Hanna et al., 2011). Currently, 
there is a shift for using different devices i.e. mobile devices to reach consumers in line to introduce/ selling organizations' brands especially in China and India. Social networking sites can be easily through these devices especially smartphones usage. .

On the other hand, using social networking will create new challenges and threats to organizations and their employees as both are sharing the same concerns in relation to social networking integrating in the workplace. Social networking will create experiments and challenges to organizations and employees in relation to privacy/security, scams/harassment, intellectual property, control and access, law/cyber-attacks, time consuming, and bullying. These negative aspects have a huge influence and risk on both organisations and employees from reputation, culture, vision and mission. A recent research (Bennett et al., 2010, Forrester Resarch, 2010, Langheinrich and Karjoth, 2010, Dwyer and Hiltz, 2007 )confirm that using social networking can benefit organizations and their employees, but in some situation can quickly destroy company reputation that took years to build and can lead to risks in productivity and legal obligation (see Figure 7). To prevent these intimidations and threats organizations should develop/adopt a set of guidelines to match their needs or using the guidelines which are mainly focusing on these concerns.

Figure 7: Organization - Social Network and Employees- Social Network (Negative)

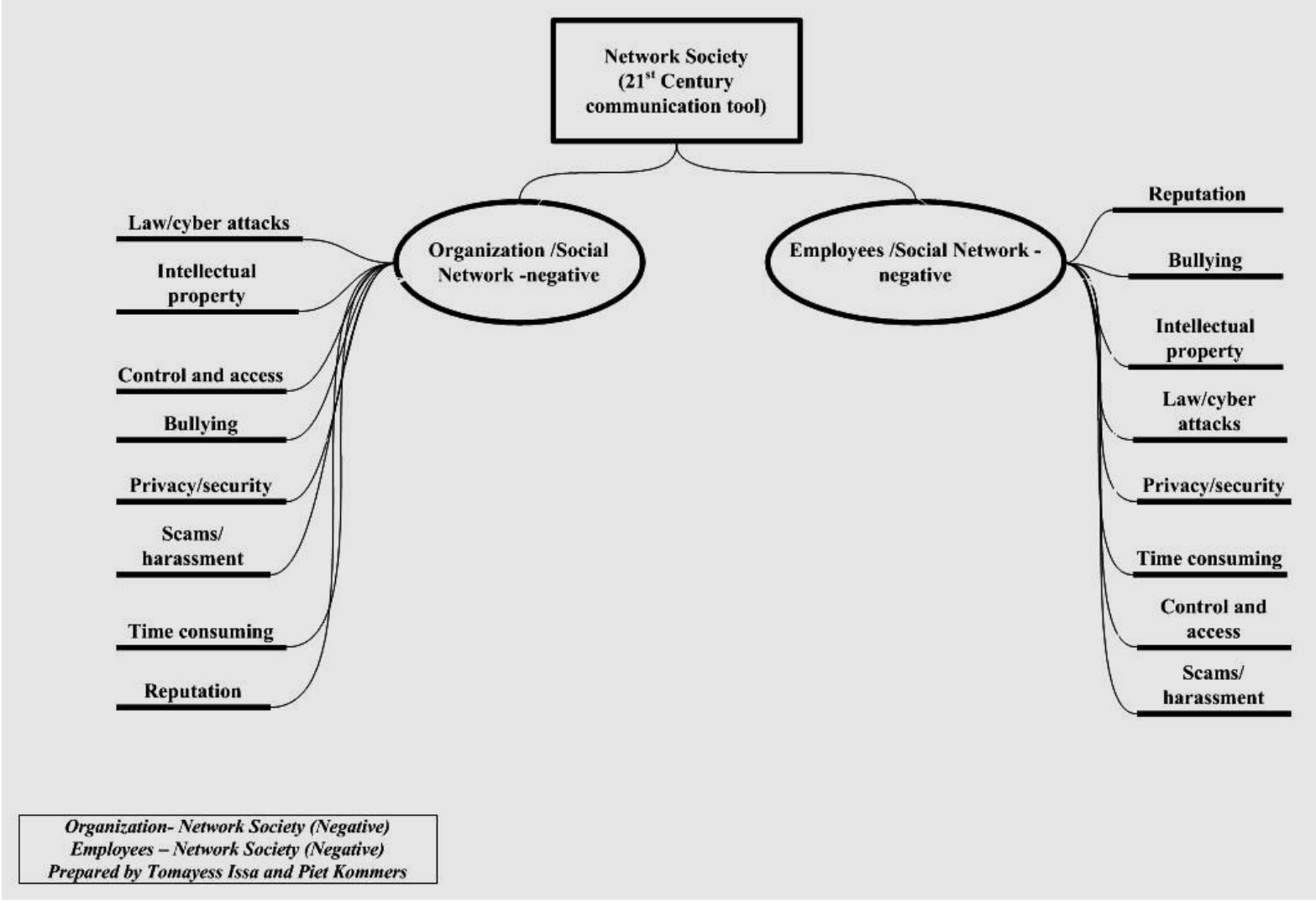

Several studies (Fitzpatrick, 2010, Kaplan and Haenlein, 2010, Landman et al., 2010, McKenna, 2010) provide several guidelines and instructions for organizations and individuals for implementing social networking sites. These guidelines mainly focus in respect to legal risks, security, privacy and reputation. Therefore, organizations, management and employees should consider these guidelines, or policies before the implementation. On the other hand, new guidelines should be implemented or developed to match organizations and employees' requirements and needs. 
Form the employee's perspective, it was noted integration social networking in the work sector (see Figure 8) will allow employees to obtain/develop new: skills, communications, networking, and becoming more innovative and productive in their work. Beside the above, social networking will bring freedom and flexibility in the organization which driven it to be more immovability and stability (Arevalo, 2010, Thakurta, 2010, Curtis et al., 2010 , DiStaso et al., 2011).

Figure 8 Employees - Social Network Benefits

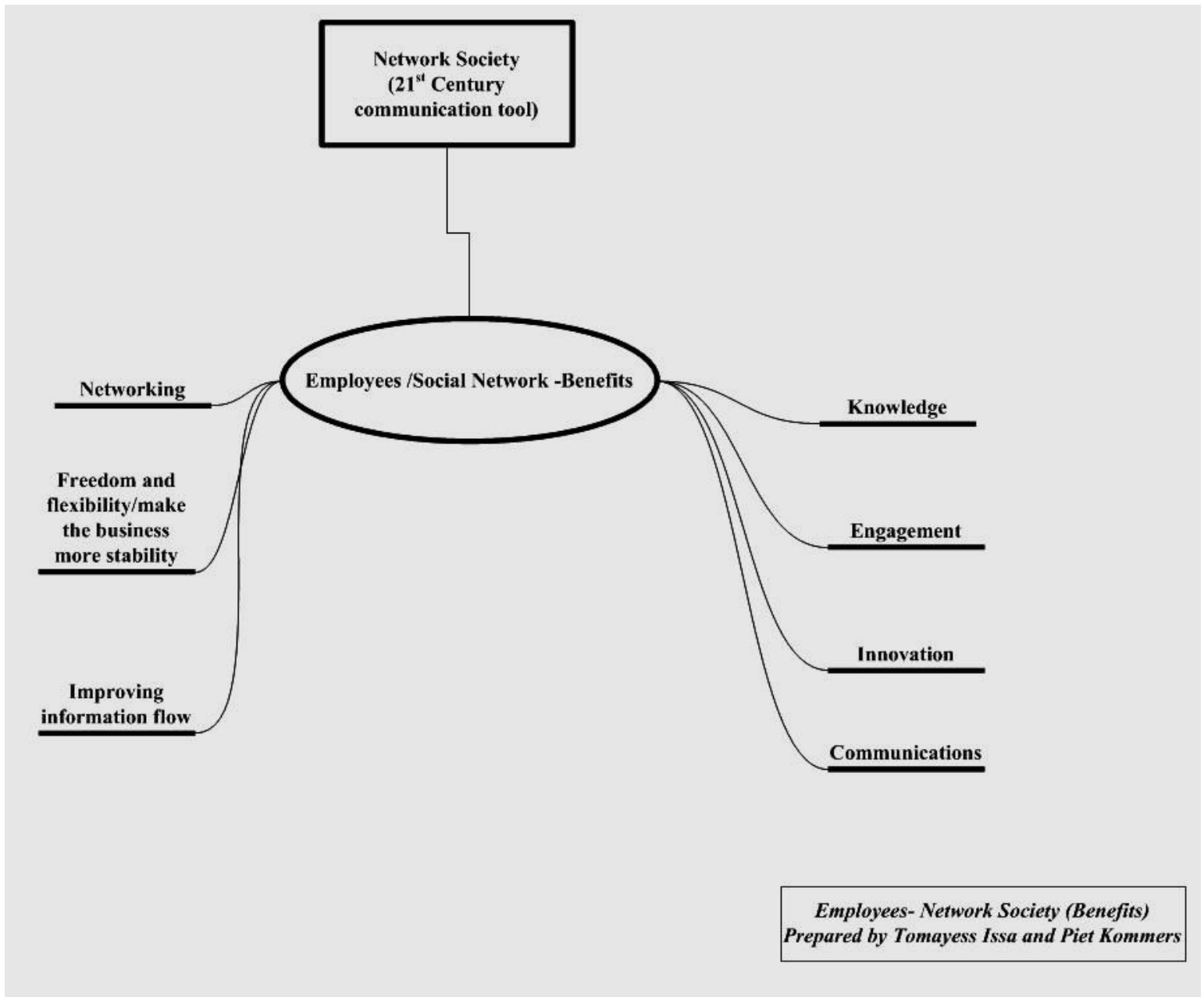

The final sector to be discussed in this study is the health sector; the researchers examined and investigated how social networking sites can assist the health sector for the education intention. The integration between social networking sites and e-health is emerging as an important platform of communication, collaboration and the most important aspect is education health information (Hanson et al., 2011, Kontos et al., 2010 ). With the same indication Lefebvre (2007) indicate that social networking is not a new way to 'reach' people - it is an 'attract and join' space'. Previously, users need to interact and communicate with others via several platforms from telephone, face to face, or traditional methods to obtain their needs (Kommers, 2011 ). However, currently the situation is different as users can interact and acquire the information via the Internet or social networking sites by asking their friends or internet users regarding his/her needs. Majority of users confirmed that using this method is more convenient and easier compared with the traditional methods; however vast challenges and threats from security, privacy, and cognitive, social and physical developments will be occurred by using this method. 
From the health sector, it was noted that $60 \%$ of physicians already use/interested in using physician communities, while the rest are unconcern/uninterested of using the social networking to interact and connect with their patients (iHealthBeat, 2009). Moreover, under the social networking sites especially Twitter, there are 140 health care. These health care locations are mainly focus on specific issues, from risk management communication, augmenting telemedicine, exercise management and encouragement, weight management and support and others. These locations aims to share/interact the latest knowledge and cutting edge with their patients (Baumann, 2009). With the same demonstration Boulos and Wheelert, (2007) designate that social networking can manage online information and knowledge repositories including medical and health information and the most important aspect will allow physicians and patients to access these records in line to exchange, communicate, collaborate information between physicians and their patients. There are various social networking sites which are mainly focus on health i.e. Medicine Group, Doc2Doc, DocCheck Faces; DoctorNetworking; DoctorsHangout, Healtheva and others (Medicalicious, 2009 ). These websites aimed to ease doctors, surgeons, specialists nurses and students their career load, enhance their knowledge, secure cutting edge knowledge, and to obtain valuable connections by joining these websites.

Currently there are a large number of patients and physicians are using the social networking sites for exchanging ideas and health information and resources. This type of relationship can develop a positive relationship between patients and physicians in relation to trust, confidence and virtual support. However, according to Cullen (2010) patients without internet access may become relatively more disadvantaged in relation to health matters, and there is some evidence that this may be occurring.

This technology is providing an enormous benefits to the health sector as patients can interact and exchange information with their physicians without any graphical boundaries, and this interaction will allow patients to earn new/update their knowledge in respect to the health issues. A recent study by Hanson et al. (2011) confirm that using social networking usage in the health sector will have a significant benefit on patients, physicians, and students to obtain cutting edge knowledge and building excellent interaction and collaboration between themselves.

However, patients, physicians, surgeons, specialists nurses and students must consider the barriers, challenges and threats behind using social networking sites from ethics, security, privacy, cyber-attacks, reputation, legal issues and physicians' workload (Keenan, 2009 , Bennett et al., 2010, Forrester Resarch, 2010, Lester and Perini, 2010, Lin and Lu, 2011, Swensrud, 2011, Hanson et al., 2011). Hanson et al.(2011, p.201) add another challenge of social networking usage in the health sector "employers monitoring or blocking social networking sites at work, difficulty of use of social networking especially among older health educator, and the lack of belief that using social networking technologies would enhance job performance'. These barriers are essential in the health sector and these barriers should be considered by the health sector before the social networking implementation (see Figure 9). 


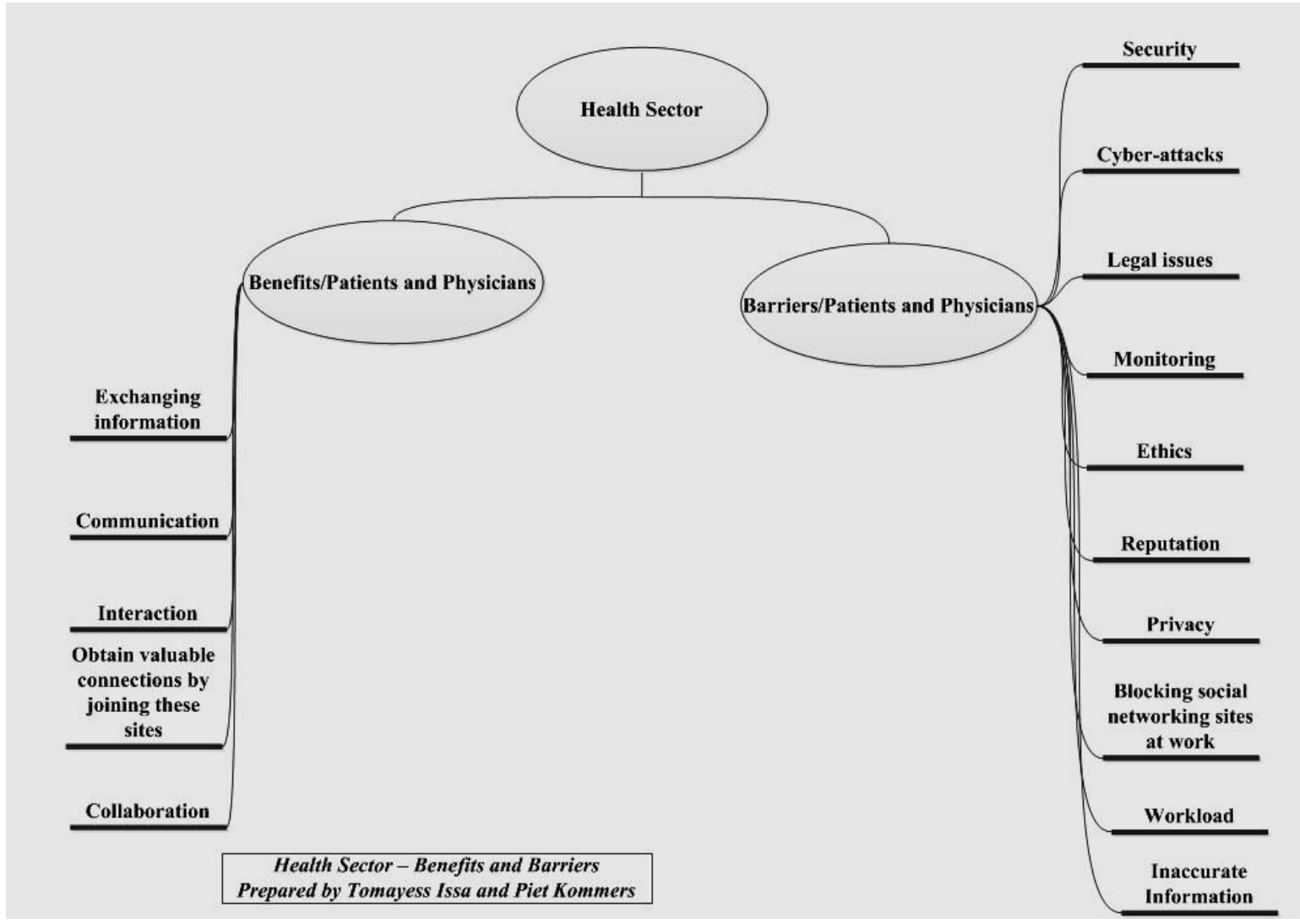

Therefore to solve these challenges and threats in the health sector, a set of guidelines should be develop for appropriate online behaviour for employees and patients for preventing these problems especially the legal problems, and posting an inaccurate information under these sites including blogs and other platforms.

\section{Conclusion}

This article discussed and investigated the social networking usage from three perspectives: organization, academics and health sectors. Under each sector the researchers discussed each perspective from: teachers, students, employees and organizations, patients and physicians and later the paper discussed the barriers and benefits of each sector by using social networking websites. From the literature review it was noted that social networking started to play a major role in these sectors in respect to the communication, marketing, collaboration, exchange information and gaining cutting edge knowledge and skills. However, social networking can fetch different challenges from training, workload, security, privacy, ethics, reputation, legal issues and cyber-attacks. Therefore, to cope with these challenges and threats a set of guidelines should be developed for appropriate online behaviour. Finally, this study with it empirical evidence raised the alarm to these sectors in relation to the problems and benefits behind social networking usage in their sectors, as responsibility lay first on each individual who is working in these sectors as s/he must think seriously how to tackle down the current problems in their workplace and acquire the rewards of social networking. Further research will be carried out by the researchers to examine and investigate other sectors with different criteria. 


\section{References}

ALEXA. 2011. The web Information Company: Alexa Top 500 Gtlobal Sites [Online]. Available: http://www.alexa.com/topsites/global [Accessed 12 Nov 2011 ].

AMICHAI-HAMBURGER, Y. \& HAYAT, Z. 2011. The impact of the Internet on the social lives of users: A representative sample from 13 countries. Computers in Human Behavior, 27585 - 589

ANONYMOUS 2009. Social networking and the workplace Making the most of web 2.0 technologies. Strategic direction, 25, 20.

AREVALO, J. 2010. Critical Reflective Organizations: An Empirical Observation of Global Active Citizenship and Green Politics. Journal of Business Ethics, 96, 299-316.

BAAMS, L., JONAS, K., UTZ, S., BOS, H. \& VUURST, L. 2011 Internet use and online social support among same sex attracted individuals of different ages. Computers in Human Behavior, Article in Press 1 - 8

BAUMANN, P. 2009140 Health Care uses for Twitter [Online]. Available: http://philbaumann.com/2009/01/16/140-health-care-uses-for-twitter/ [Accessed 22 Nov 2011$]$.

BENNETT, J., OWERS, M., PITT, M. \& TUCKER, M. 2010. Workplace impact of social networking Property Management 28, 138 - 148.

BOULOS, M. \& WHEELERT, S. 2007. The emerging Web 2.0 social software: an enabling suite f sociable technologies in health and health care education. Health Information and Libraries Journal, 24, 2-23.

BRYNE, S. \& LEE, T. 2011 Toward Predicting Youth Resistance to Internet Risk Prevention Strategies. Journal of Broadcasting \& Electronic Media, 55, 90 - 113

BUCK, S. 2011. How the World Uses Social Networks [INFOGRAPHIC] [Online]. Available: http://mashable.com/2011/09/23/world-social-networks-infographic/ [Accessed 22 Nov 2011].

BURRUS, D. 2010. Social Networks in the Workplace: The Risk and Opportunity of Business. Strategy and Leadership, 38, 50-53.

CARR, N. 2008. Is Google Making Us Stupid? The Atlantic Monthly.

CORREA, T., HINSLEY, A. \& GIL DE ZUNIGA, H. 2010. Who Interacts on the Web?: The Intersection of Uers' Personality and Social Media Use Computers in Human Behavior 26, 247 - 253.

CULLEN, K. 2010. Health - Work Research Centre (Study on the Social Impact of ICT) - Topic Report 3 (D7.2) In: UNIVERSITÄT SIEGEN, F. W. U. N. M. \& GERMANY (eds.).

CURTIS, L., EDWARDS, C., FRASER, K., GUDELSKY, S., HOLMQUIST, J., THORNTON, K. \& SWEETSER, K. 2010 Adoption of Social Media for Public Relations by NonProfit Organizations. Public Relations Review 36, 90 - 92.

DABBAGH, N. \& KITSANTAS, A. 2011. Personal Learning Environments, social media, and self-regulated learning: A natural Formula for connecting formal and informal learning Internet and Higher Education

DEANDREA, D., ELLISON, N., LAROSE, R., STEINFIELD, C. \& FIORE, A. 2011. Serious social media: On the use of social media for improving students' adjustment to college Internet and Higher Education.

DIGIZEN.ORG. n.d. WHAT ARE SOCIAL NETWORKING SERVICES? [Online]. Available: http://www.digizen.org/downloads/social-networking-overview.pdf [Accessed 22 Nov 2011].

DISTASO, M., MCCORKINDALE, T. \& WRIGHT, D. 2011. How Public relations executives perceive and measure the impact of social media in their organizations Public Relations Review, 37, 325 - 328

DWYER, C. \& HILTZ, S. P., K. Year. Trust and Privacy Concern Within Social Netowrking Sites: A comparison of Facebook and MySpace In: Thirteenth Americas Conference on Information Systems (AMCIS) 2007 Keystonee, Colorado 1 - 13.

EUROPEAN TRAVEL COMMISSION. 2011. Social Networking and UGC [Online]. Available: http://www.newmediatrendwatch.com/world-overview/137-socialnetworking-and-ugc [Accessed 16 Nov 2011].

FITZPATRICK, A. 2010. Facebook and social networking - inappropriate use by employees [Online]. Available: http://www.gadens.com.au/PublicationsView.aspx?documentid=1704\#article2 [Accessed 22 Nov 2011].

FORRESTER RESARCH 2010. Social Networking in The Enterprise: Benefits and Inhibitors USA: Forrester Resarch 
HANNA, R., ROHM, A. \& CRITTENDEN, V. 2011. We're all connected: The power of the social media ecosystem Business Horizons, 54, 265 - 273

HANSEN, D., SHNEIDERMAN, B. \& SMITH, M. 2011. Analyzing social media networks with NodeXL: Insights from a connected world, Boston Elsevier

HANSON, C., WEST, J., NEIGER, B., THACKERAY, R., BARNES, M. \& MCINTRYE, E. 2011. Use and Acceptance of Social Media among Health Educators American Journal of Health Education 42, 197 - 204.

HARRIS, J. 2010 How the internet is altering your mind [Online]. Available: http://www.guardian.co.uk/technology/2010/aug/20/internet-altering-your-mind [Accessed 15 May 2011].

HEW, K. 2011. Reivew: Students' and teachers' use of Facebook. Computers in Human Behavior, 27, 662 - 676.

IHEALTHBEAT. 2009. How Well are Online Physician Communities Being Received? [Online]. Available: http://www.ihealthbeat.org/Data-Points/2009/How-WellAre-Online-Physician-Communities-Being-Received.aspx [Accessed 22 Nov 2011 ].

INTERNET WORLD STATS. 2011. Internet World Stats [Online]. Available: http://www.internetworldstats.com/stats.htm [Accessed 22 Nov 2011 ].

KANE, K., ROBINSON, J. \& BERGE, Z. 2010. Tapping into social networking Collaborating enhances both knowlege management and e-learning VINE: The journal of information and knowledge management systems, 40, 62-70.

KAPLAN, A. M. \& HAENLEIN, M. 2010. Users of the world, unite! The challenges and opportunities of Social Media. Business Horizons, 53, 59-68.

KAYA, T. 2010. CUNY social network mixes scholarship with Facebookstyle friendship. [Online]. Chronicle of Higher Education. Available: http://chronicle.com/blogs/wiredcampus/cuny-social-network-mixesscholarshipwith-_facebook-style-friendship/27266 [Accessed 12 Nov 2011].

KEARNS, L. \& FREY, B. 2010. Web 2.0 Technologies and Back Channel Communication in an Online Learning Community. TechTrends, 54, 41 - 54.

KEENAN, A. 2009 Sociability and Social Interaction on Social Networking Websites Library Review 58, 438 - 450

KELIN, K. 2008. Are Social Networking Sites Useful for Business? [Online]. Available: http://www.businessweek.com/print/smallbiz/content/aug2008/sb2008086_3460 94.htm [Accessed 22 Nov 2011].

KIETZMANN, J., HERMKENS, K., MCCARTHY, I. \& SILVESTRA, B. 2011. Social Media? Get Serious! Understanding the Functional Building Blocks of social Media Business Horizons, 54, 241 - 251.

KOMMERS, P. 2011 Future Developments in E-Simulations for Learning Soft Skills in the Health Professions In: HOLT, D., SEGRAVE, S. \& CYBULSKI, J. (eds.) ESimulations for Educating the Professions in Blended Learning Environments. IGI Publisher.

KONTOS, E., EMMONS, K., PULEO, E. \& VISWANATH, K. 2010 Communication Inequalities and Public Health Implications of Adult Social Networking Site Use in the United States. Journal of Health Communication 15, 216 - 235.

LANDMAN, M. P., SHELTON, J., KAUFFMANN, R. M. \& DATTILO, J. B. 2010. Guidelines for Maintaining a Professional Compass in the Era of Social Networking. Journal of Surgical Education, 67, 381-386.

LANGHEINRICH, M. \& KARJOTH, G. 2010. Social networking and the risk to companies and institutions. Information Security Technical Report, 15, 51-56.

LEE, S. 2009 Online Communication and Adolescent Social Ties: Who benefits more from Internet use? Journal of Computer-Mediated Communication, 14, 509 531

LEFEBVRE, R. 2007. Data on the Safety of Health Social Network Sites Available from: http://socialmarketing.blogs.com/r_craiig_lefebvres_social/ehealth/ [Accessed 22 Nov 2011 ].

LESTER, J. \& PERINI, M. 2010. Potential of Social Networking Sites for Distance Education Student Engagement Online Education 15067 - 77.

LIN, K. \& LU, H. 2011. Why people use social networking sites: An empirical study integrating network externalities and motivation theory. Computers in Human Behavior, 27, 1152 - 1161.

MALITA, L. 2011. Social Media time management tools and tips Procedia Computer Science 3, 747 - 753. 
MCKENNA, B. 2010. Social networking: The 'what not to do' guide for organisations. . InfoSecurity, 7, 22 - 24.

MEDAGLIA, R., ROSE, J., NYVANG, T. \& SAEBO, O. Year. Characteristics Of Social Networking Services. In: MCIS 2009, 2009 Athens

MEDICALICIOUS. 2009 Top 25 Social Networking Sites for Healthcare \& Medical Professionals [Online]. Available: http://medicallabtechnicianschool.org/2009/top-25-social-networking-sites-forhealthcare-medical-professionals/ [Accessed 22 Nov 2011 ].

MITCHELL, M., LEBOW, J., URIBE, R., GRATHOUSE, H. \& SHOGER, W. 2011. Internet use, happiness, social support and introversion: A more fine grained analysis of person variables and internet activity. Computers in Human Behavior, Article in Press 1- 5

MOKHTARI, K., REICHARD, C. \& GARDNER, A. 2009 The Impact of Internet and Television Use on the Reading Habits and Practices of College Students. Journal of Adolescent \& Adult Literacy, 52, 609 - 619

ROSENBERG, M. 2011. Current World Population [Online]. Available: http://geography.about.com/od/obtainpopulationdata/a/worldpopulation.htm [Accessed 22 Nov 2011].

SHAW, L. H. \& GANT, L. M. 2002. In Defense of the Internet: The Relationship between Internet Communication and Depression, Loneliness, Self-Esteem, and Perceived Social Support. CyberPsychology \& Behavior, 5, 157-171.

STRUCK, R., HYNASLAHTI, H., LIPPONEN, L., VESTERINEN, O., VHTIVUORIHANNINEN, S., MYLLARI, J. \& TELLA, S. 2011. Podcasts as LearnerCreated Content in Higher Education International Journal of Online Pedagogy and Course Design 1, 20 - 30

SUN, S. 2011. The Internet Effects on Students Communication at Zhengzhou Institute of Aeronautical Industry Management Advances in Computer Science, Environment, Ecoinformatics and Education 218, 418 - 422.

SWENSRUD, K. 2011. Best Practices for Enterprise Social Networking [Online]. Available: http://thenextweb.com/socialmedia/2011/04/18/best-practices-forenterprise-social-networking/ [Accessed 16 Nov 2011].

THAKURTA, R. 2010. Management of Requirement Volatility - A Study of Organizational Competency and How it is influenced by the Project Environment Journal of Information Technology Management XXI, 24 - 34

THOMPSON, L., DAWSON, K., FERDIG, R., BLACK, E., BOYER, J., COUTTS, J. \& PARADISE, N. 2008. The Intersection of Online Social Networking with Medical Professionalism Journal of General Internal Medicine 23, 954 - 957.

VAN DEURSEN, A. J. A. M., VAN DIJK, J. A. G. M. \& PETERS, O. 2011. Rethinking Internet skills: The contribution of gender, age, education, Internet experience, and hours online to medium- and content-related Internet skills. Poetics, 125 144.

VERDICK.ORG;. 2011. Positive Effects of Internet Usage on Child Development [Online]. Available: http://www.verdick.org/child-development-and-theinternet/child-dev-pos [Accessed 25 Sept 2011].

VERHOEVAN, P., TENCH, R., ZERFASS, A., MORENO, A. \& VERCIC, D. 2011. How European PR Practitioners handle digital and social media. Public Relations Review.

WADDINGTON, J. 2011. Social Networking: The Unharnessed Educational Tool Undergraduate Research Journal of UCCS, 4.1, 12 - 18.

WALTHER, J., VAN DER HEIDE, B., TONG, S., CARR, C. \& ATKIN, C. 2010 Effects of Interpersonal Goals on Inadvertent Intrapersonal Influence in ComputerMediated Communication. Human Communication Research, 36, 323 - 347

WAUTERS, R. 2011. Over 1 Billion People Use Social Networks Today, And Other Stats [Online]. Available: http://techcrunch.com/2011/09/14/over-1-billion-peopleuse-social-networks-today-and-other-stats/ [Accessed 22 Nov 2011].

WEAVER, A. \& MORRISON, B. 2008. Social Networking Computer 41, 97 - 100

WENGER, E., WHITE, N. \& SMITH, J. 2009. Digital Habitats; stewarding technology for communities, USA, CPsquare. 
ZAMORANO, M., RODRIGUEZ, M., RAMOS-RIDAO, A., PASADAS, M. \&

PRIEGO, I. Year. An Innovation Teaching Experience Following Guidelines of European Space of Higher Education in the Interactive Learning In:

MILTIADIS D. LYTRAS, PATRICIA ORDÓÑEZ DE PABLOS, ADRIAN ZIDERMAN, ALAN ROULSTONE, HERMANN A. MAURER \& IMBER, J.

B., eds. Knowledge Management, Information Systems, E-Learning, and Sustainability Research - Third World Summit on the Knowledge Society, WSKS 2010,, 2010 Greece. 545 - 554. 